\title{
Efeito de fosfito de potássio no crescimento e na densidade micelial do Fusarium solani do maracujazeiro
}

\author{
Geraldo Gomes Rocha Sobrinho ${ }^{1, *}$, Gisele Brito Rodrigues ${ }^{1}$, Armínio Santos ${ }^{1}$, Waldir Cintra de Jesus Junior ${ }^{2}$, Quelmo \\ Silva de Novaes ${ }^{1}$.
}

${ }^{1}$ Universidade Estadual do Sudoeste da Bahia - UESB, Departamento de Fitotecnia e Zootecnia - DFZ, Caixa Postal 95, CEP 45031-300, Vitória da Conquista, BA - Brasil. ${ }^{2}$ Universidade Federal de São Carlos. Campus Lagoa do Sino, Aracaçu, CEP 18290-000 - Buri, SP - Brasil. *Parte da dissertação de mestrado do primeiro autor, apresentada à Universidade Estadual do Sudoeste da Bahia no ano de 2015.

Autor para correspondência: Quelmo Silva de Novaes (qsnovaes@uesb.edu.br)

Data de chegada: 05/11/2015. Aceito para publicação em: 21/01/2016.

$10.1590 / 0100-5405 / 2139$

\section{RESUMO}

Rocha Sobrinho, G.G.; Rodrigues, G.B.; Santos, A.; Jesus Junior, W.C.; Novaes, Q.S. Efeito de fosfito de potássio no crescimento e na densidade micelial do Fusarium solani do maracujazeiro. Summa Phytopathologica, v.42, n.2, p.180-182, 2016.

\footnotetext{
Objetivou-se com este trabalho avaliar o efeito de fosfito de potássio sobre o crescimento e a densidade micelial de Fusarium solani isolado de maracujazeiros. A verificação do efeito de fosfito de potássio sobre $F$. solani consistiu na diluição de $0,1,10,50,100,250,500,750$ e 1000 ppm do produto em BDA, com posterior avaliação do crescimento e da densidade micelial do fungo. A influência do $\mathrm{pH}$ do meio BDA, no crescimento de $F$. solani, foi testada pela diluição de ácido clorídrico no meio até a obtenção dos valores de $\mathrm{pH}$ idênticos àqueles das placas contendo as concentrações de fosfito de potássio. Após dez dias de incubação foi medido o crescimento do fungo. A mensuração da densidade micelial de $F$. solani foi realizada por meio da
}

leitura de absorbância a $405 \mathrm{~nm}$, de discos contendo micélio do fungo, em leitor de ELISA. O efeito fungicida ou fungistático de fosfito de potássio foi testado repicando-se o F. solani, proveniente das concentrações que o inibiu, para meio BDA puro e observando o seu posterior crescimento ou não. O fosfito de potássio inibiu o crescimento e a densidade micelial de $F$. solani, significativamente, a partir de $50 \mathrm{ppm}$. Não houve diferença significativa no crescimento de $F$. solani dentro da faixa de $\mathrm{pH}$ testada. $\mathrm{O}$ F. solani cresceu em meio BDA puro, após ser repicado do meio de cultura contendo as concentrações de fosfito de potássio que o inibiu, indicando ser um efeito fungistático do mesmo sobre o fungo.

Palavras-chave: Podridão do colo e raízes, controle alternativo, fusariose, maracujá.

\begin{abstract}
Rocha Sobrinho, G.G.; Rodrigues, G.B.; Santos, A.; Jesus Junior, W.C.; Novaes, Q.S. Effect of potassium phosphite on the mycelial growth and density of Fusarium solani in passion flower vine. Summa Phytopathologica, v.42, n.2, p.180-182, 2016.

The aim of this study was to evaluate the effect of potassium phosphite on the mycelial growth and density of $F$. solani isolated from passion flower vines. Verification of the potassium phosphite effect on $F$. solani consisted in diluting $0,1,10,50,100,250,500,750$ and $1000 \mathrm{ppm}$ of the product in PDA medium, subsequently evaluating the mycelial growth and density of the fungus. Influence of the $\mathrm{pH}$ of the PDA medium on F. solani growth was tested by diluting hydrochloric acid in the medium until the obtained $\mathrm{pH}$ values were identical to those of the plates containing the potassium phosphite concentrations. After ten days of incubation, fungal growth was measured. F. solani mycelial density was measured by reading the

absorbance at $405 \mathrm{~nm}$ of discs containing fungal mycelium in an ELISA reader. The fungicide or fungistatic effect of potassium phosphite was tested by transferring $F$. solani, from the concentrations that had inhibited it, to pure PDA medium and by observing whether there was further growth or not. Potassium phosphite significantly inhibited the mycelial growth and density of $F$. solani, from $50 \mathrm{ppm}$. There was not any significant difference in $F$. solani growth within the tested $\mathrm{pH}$ range. F. solani grew on pure PDA medium, after its transference from the culture medium containing the potassium phosphite concentration that had inhibited it, which indicates a fungistatic effect on the fungus.
\end{abstract}

Keywords: Root and collar rot, alternative control, fusariosis, passion fruit.

O Brasil é o maior produtor mundial de maracujá-amarelo (1). No entanto, a produtividade média é consideravelmente baixa em relação ao seu potencial produtivo. Isso se deve a diversos fatores, sendo o de maior destaque a incidência de doenças. Estas depreciam os frutos, diminuem e oneram a produção e não possuem, para as principais doenças, um controle efetivo (2).

Presente em todos os estados brasileiros e principais regiões produtoras de maracujá do mundo, a podridão do colo e raízes, causada principalmente pelo fungo Fusarium solani (Mart.) Sacc., constitui-se uma das mais importantes doenças do sistema radicular do maracujazeiro (3). Até o momento, medidas de controle efetivas contra esta doença, são desconhecidas. Entretanto, um recente estudo demostrou que o crescimento in vitro de $F$. solani, pode ser inibido satisfatoriamente por fosfito de potássio (3), abrindo novas perspectivas para estudos que visem o controle deste fungo.

Uma concentração ideal, bem como a influência do $\mathrm{pH}$ ácido do fosfito de potássio no crescimento micelial do $F$. solani do maracujazeiro, ainda não são conhecidos, necessitando assim de estudos complementares.

Nesse sentido, objetivou-se com este trabalho avaliar o efeito 

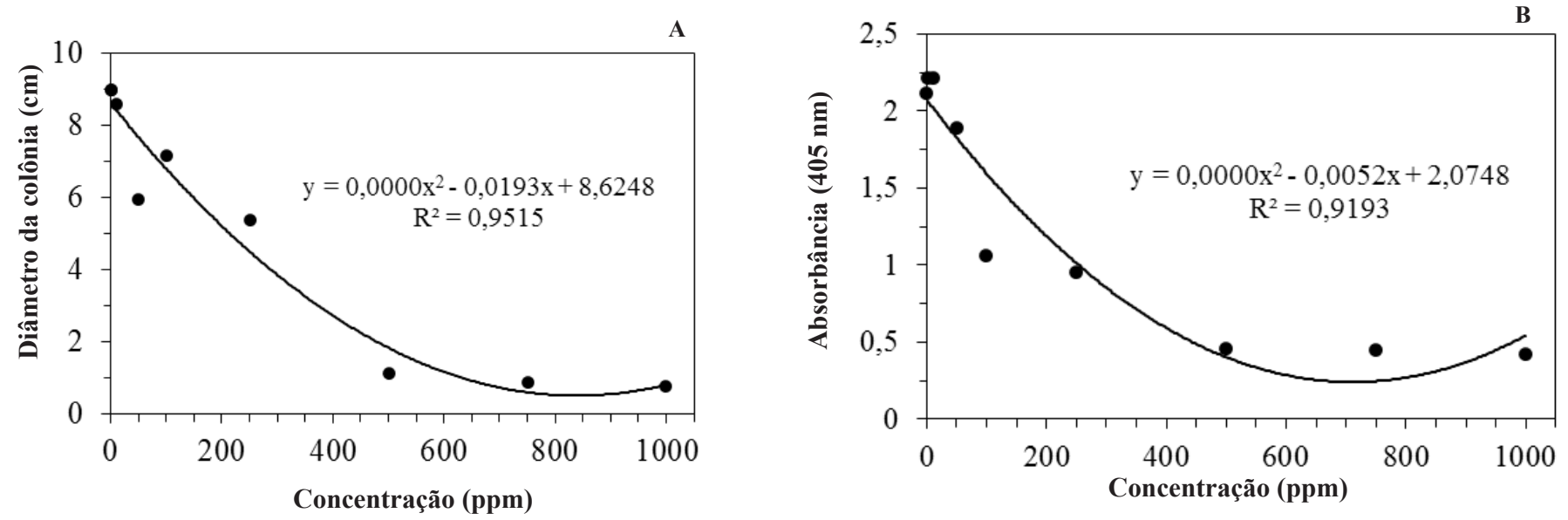

Figura 1. Crescimento micelial (A) e absorbância média (B) de colônias de Fusarium solani, isoladas de maracujazeiro amarelo, submetidas a diferentes concentrações de fosfito de potássio no meio de cultura batata-dextrose-ágar.

in vitro de fosfito de potássio (00-40-20), sobre o crescimento e a densidade micelial de $F$. solani isolado de maracujazeiro.

Para o teste de inibição, o fosfito de potássio foi adicionado em meio de cultura batata-dextrose-ágar (BDA), fundente entre $45-50^{\circ} \mathrm{C}$, diluídos em série, de modo a se obter as respectivas concentrações do produto comercial: 0, 1, 10, 50, 100, 250, 500, 750 e 1000 ppm. Após o preparo, $20 \mathrm{~mL}$ de meio de cultura foi vertido em cada placa de Petri com nove centímetros de diâmetro.

Discos de BDA de $7 \mathrm{~mm}$ de diâmetro, colonizados por F. solani isolado de raízes de maracujazeiro com sintomas de podridão do colo e raízes, foram transferidos para o centro de cada placa de Petri. Após as repicagens, as placas foram incubadas em BOD com fotoperíodo de 12 horas, a $25^{\circ} \mathrm{C}$, por dez dias, quando o fungo, no tratamento testemunha, alcançou a borda da placa. O delineamento experimental foi o inteiramente casualizado (DIC), com 09 tratamentos e 05 repetições, sendo cada placa considerada uma repetição.

Ao final dos dez dias de incubação, avaliou-se o crescimento e a densidade micelial das colônias de F. solani.

A avaliação do crescimento micelial foi feita medindo-se o diâmetro médio das colônias com o auxílio de uma régua milimétrica. Para a avaliação da densidade micelial, quatro discos de BDA, contendo o fungo, foram retirados a uma distância de $2 \mathrm{~cm}$ do centro de cada placa. Estes discos, de $7 \mathrm{~mm}$ de diâmetro, foram acondicionados individualmente em cada poço de uma placa de ELISA, as quais correspondem ao mesmo diâmetro. Cada disco foi considerado uma repetição. A absorbância de cada um dos poços foi medida em leitor de ELISA, utilizando-se filtro de $405 \mathrm{~nm}$.

Os resultados do crescimento e da densidade micelial foram submetidos às análises de variância e de regressão, com o auxílio do programa estatístico SISVAR 5.6 (4).

Para avaliar o efeito da acidificação dos meios pela adição de fosfito de potássio, mensurou-se os valores do $\mathbf{p H}$ de cada concentração no meio BDA e preparou-se meios BDA com o $\mathrm{pH}$ correspondente, sendo eles: pH 5,57 (0 e 1 ppm); pH 5,56 (10 ppm); pH 5,48 (50 ppm); pH 5,38 (100 ppm); pH 5,18 (250 ppm); pH 5,03 (500 ppm); pH 4,74 (750 ppm) e $\mathrm{pH} 4,51$ (1000 ppm). O ajuste do $\mathrm{pH}$ foi realizado utilizando-se soluções de $\mathrm{HCl}$. Em seguida, foram repicados discos de $7 \mathrm{~mm}$ de diâmetro de BDA colonizado por $F$. solani, para cada placa, as quais foram incubadas a $25^{\circ} \mathrm{C}$, com fotoperíodo de 12 horas, por dez dias.

O delineamento experimental foi o DIC, com 08 tratamentos e 05 repetições, sendo cada placa considerada uma repetição. Avaliou-se o diâmetro médio das colônias de $F$. solani, aos 10 dias após a repicagem, quando o fungo, no tratamento testemunha, alcançou a borda da placa. Os resultados foram submetidos à análise de variância com o auxílio do programa estatístico SISVAR 5.6 (4).

Para averiguar se o fosfito de potássio apresentava efeito fungicida ou fungistático sobre $F$. solani, discos colonizados pelo fungo foram repicados das placas contendo as concentrações do produto, as quais promoveram a inibição do fungo, para placas com BDA puro. Foram utilizados dois discos para cada concentração. Em seguida, as placas foram incubadas a $25^{\circ} \mathrm{C}$, com fotoperíodo de 12 horas. A avaliação consistiu na verificação do crescimento ou não da colônia de $F$. solani.

O fosfito de potássio apresentou efeito inibitório significativo sobre o crescimento e a densidade micelial de $F$. solani a partir da concentração de 50 ppm, intensificando a inibição com o aumento das concentrações do produto no meio BDA até a concentração máxima testada de 1000 ppm (Figura 1).

O modelo de regressão quadrático foi o que melhor ajustou-se aos valores de diâmetro e absorbância média das colônias de $F$. solani, crescidas em diferentes concentrações de fosfito de potássio no meio BDA. A concentração inibitória de $50 \%$ do crescimento e densidade micelial do $F$. solani foi de 213 e 177 ppm, respectivamente.

$\mathrm{O}$ efeito direto de fosfito de potássio sobre outros fungos também já foi observado por outros autores, como na redução do crescimento micelial de Colletotrichum lindemuthianum e esporulação de Fusarium oxysporum f. sp. phaseoli, patógenos do feijoeiro (Phaseolos vulgaris L.), relatado por Caixeta et al. (5), utilizando concentrações de 125, 250 e 500 ppm. Araújo et al. (6) relataram 94\% de inibição, in vitro, do crescimento micelial de Colletotrichum gloeosporioides, isolado de macieira (Malus domestica), com a concentração de 1500 ppm de fosfito de potássio em meio BDA.

$\mathrm{O}$ efeito fungitóxico de fosfito de potássio sobre Colletotrichum spp., isoladas de outras culturas, também foi relatado por Alexandre et al. (7), ao estudar o efeito deste produto sobre $C$. tamarilloi isolado de Jiló (Solanum gilo), e por Ogoshi et al. (8) com C. gloeosporioides em cafeeiro (Coffea arabica).

O fosfito de potássio isolado ou em associações com fungicidas também exerce controle sobre oomicetos, como Phytophthora infestans, agente causal da requeima, uma das principais doenças do tomateiro (Solanum lycopersicum) (9).

O crescimento micelial do $F$. solani não foi afetado pela variação do $\mathrm{pH}$ do meio BDA, dentro da faixa testada $(4,51$ a 5,57), sendo que, 
todas as colônias atingiram as bordas das placas ao final de 10 dias de incubação. Com base neste resultado, comprova-se o efeito isolado do fosfito de potássio na inibição do crescimento micelial do fungo.

Ao avaliar o crescimento micelial de Verticillium lecanii em meios de cultivo com pH variando entre 4,0 e 9,0, Monteiro et al. (10) também observaram que não houve grande influência do $\mathrm{pH}$ inicial sobre o fungo, que foi capaz de superar possíveis restrições impostas pelos diferentes pH's dos meios, exceto no $\mathrm{pH}$ mais ácido $(4,0)$, no qual seu crescimento foi reduzido.

O F. solani foi capaz de retomar o seu crescimento, em BDA puro, após ser repicado das concentrações acima de $50 \mathrm{ppm}$ de fosfito de potássio no meio BDA.

A avaliação da densidade micelial por leitura de absorbância refletiu com fidelidade o efeito de fosfito de potássio sobre o crescimento micelial do F. solani, podendo esta ser uma nova e importante ferramenta de avaliação.

O fosfito de potássio apresenta efeito fungistático sobre $F$. solani, inibindo, temporariamente, o seu crescimento e reduzindo a sua densidade micelial.

\section{Agradecimentos}

Os autores agradecem a Coordenação de Aperfeiçoamento de Pessoal de Nível Superior - CAPES pela concessão da bolsa de estudos do primeiro autor.

\section{REFERÊNCIAS}

1. ITI Tropicals. Passion fruit: the essential exotic flavor. Disponível em: $<$ http://www.passionfruitjuice.com/supply.php?MENU=5 >. Acesso em: 15 de Maio de 2015.

2. Fischer, I.H.; Rezende, J.A.M. Diseases of passion flower (Passiflora spp.). Pest Technology. Kagawa Ken, v. 2, p.1-19, 2008.

3. Silva, A.N.; Azevedo, G.B.; Rocha Sobrinho, G.G.; Novaes, Q.S. Efeito de produtos químicos e de Trichoderma spp. no controle de Fusarium solani do maracujazeiro. Interciencia, Caracas, v. 39, n. 6, p.398-403, 2014.

4. Ferreira, D.F. Sisvar: a computer statistical analysis system. Ciência e Agrotecnologia, Lavras, v. 35, n.6, p.1039-1042, 2011.

5. Caixeta, A.O.; Vieira, B.S.; Canedo, E.J. Efeito do fosfito de potássio sobre fungos fitopatogênicos do feijoeiro. Cerrado Agrociências. Patos de Minas, v. 3, p.35-43, 2012.

6. Araújo, L.; Valdebenito-Sanhueza, R.M.; Stadnik, M.J. Avaliação de formulações de fosfito de potássio sobre Colletotrichum gloeosporioides in vitro e no controle pós-infeccional da mancha foliar de Glomerella em macieira. Tropical plant pathology, Brasília, v. 35, n. 1, p.54-59, 2010.

7. Alexandre, E.R.; Herculano, L.M.; Silva, J.M.; Oliveira, S.M.A. Fosfitos no manejo da antracnose do jiló. Pesquisa Agropecuária Brasileira., Brasília, v. 49, n. 12, p.930-938, 2014

8. Ogoshi, C.; Abreu, M.S.; Silva, B.M.; Santos Neto, H.; Ribeiro Júnior, P.M., Resende, M.L.V. Potassium phosphite: a promising product in the management of diseases caused by Colletotrichum gloeosporioides in coffee plants. Bioscience Journal, Uberlândia, v. 29, n. 5, p.1558-1565, 2013.

9. Töfoli, J.G.; Mello, S.C.; Domingues, R.J.; Garcia Junior, O. Efeito do fosfito de potássio isolado e em mistura com fungicidas no controle da requeima do tomateiro. Arquivos do Instituto Biológico, São Paulo, v. 79, n. 9, p. 201-208, 2012.

10. Monteiro, A.C.; Barbosa, C.C.; Correia, A.D.C.B.; Pereira, G.T. Crescimento e esporulação de isolados de Verticillium lecanii sob diferentes fatores ambientais. Pesquisa Agropecuária Brasileira, Brasília, v. 39, n. 6, p. $561-565,2004$ 